\title{
Presence of Absence: Exploring the Democratic Significance of Silence
}

Mike Ananny

A theme seems to run through thinking about democratic self-governance that goes like this: people discover and manage shared social conditions by deliberating among themselves, devising solutions, and choosing representatives to speak on their behalf. A key feature of this idea is that people have a duty to express themselves in one or more ways: they speak face-to-face, create media (letters, television shows, social media posts), circulate their ideas, and build institutions that encourage and protect expression. The answer to bad speech is more speech; if you aren't speaking you aren't participating; the onus is on the individual to speak up.

My focus in this chapter is what this dominant view neglects and sometimes dismisses: namely, that the silences and absences that accompany listening, observation, and reflection are also key to communicative self-governance. In particular, I want to critique the assumption that participation means speaking and sketch the idea-using the theories of material publics increasingly common among communication and science and technology scholars - that legitimate and necessary democratic participation means making publics in ways that do not always leave visible, material traces. Speakers need listeners, but because listeners are often invisible, they can go unseen by political theorists and technologists alike and fail to appear in the communication systems and institutions that communicative self-governance requires.

This means seeing silence as political communication. Sometimes that silence is coerced and oppressive, with speakers and their voices actively censored, but sometimes that silence is voluntary and part of listening. Both types of silence-coerced and voluntary-are critical to understanding the democratic power of absence, but I try here to be somewhat agnostic and 
Instead, I try to explicate absence as a little-seen type of political participation underpins the communication infrastructures shaping much of contemporary online life. I try to argue that absence is a type of public participation that - when seen and valued - offers new ways to think about what's being communicated, by whom, to whom, in what contexts, and with what effects. Appreciating the complexity and force of silence can help us see digital publics differently. Since its early incarnations, scholars and advocates alike have heralded the internet as a new type of public space in which participation through digital information represents new types of constituencies and forms of representation.

The internet has often and optimistically been seen as a way to speak-to share opinions, form associations, experiment with new ideas, uncover forms of power, and advocate for change. Despite the early warnings of often marginalized critics about the internet's structural inequalities and the challenges of too neatly mapping digital technology, network associations, and distributed mediation onto political agency (Agre, 2002; Baker, 2002; Barber, 2004; Brook \& Boal, 1995; Dahlberg, 2001; Gandy, 1993; Hindman, 2008; Silver \& Massanari, 2006), the early, dominant image of the internet was as a flat, open, networked, marketplace-like space (Benkler, 2003, 2006; Shirky, 2008) in which low costs of information production and circulation were presumed to translate into robust political life (Sunstein, 2001). A perfect storm of undervaluing listening arose when these celebrations of digital speech were joined by a burst of scholarly interest in participatory cultures and online communities (Gillmor, 2004; Jenkins, 2006; Rheingold, 1993); the idea that online listening was unethical "lurking," free-riding, and a participation problem to be solved (Bishop, 2007; Preece, Nonnecke, \& Andrews, 2004; Sun, Rau, \& Ma, 2014); and commercial imperatives of advertising-fueled technology companies eager to mine user-generated content for patterns that they could use to commodify users. Speaking, expression, and actions that left visible traces were privileged over listening, observation, and participation that couldn't be easily commodified. Online participation was framed as the visible traces - texts, sounds, images - of the content creator. Silences and absences were politically suspicious, suggested the Luddites, went against the grain of participatory culture, and were commercially unprofitable. The dominant image of the digital public sphere was as a place for speakers, not listeners.

What would it mean to take seriously silence and absence as critical dynamics of political participation - and try to find evidence for them in today's communication infrastructures? Aligned with other authors in this volume-such as Ford's use of self-organizing technological systems to re- 
imagine core principles of democratic governance, and Lee, Levi, and Brown's vision of a community-centered and computationally supported collaborative ecosystem (chapter 8)-I want to explore the silences and absences of sociotechnical systems as ways to think differently about democratic, communicative self-governance.

I try here to trace the significance of silence by showing how it appears in both voluntary and involuntary dimensions of communication systems. In the first part of the chapter, through a series of examples, I try to show that intentional or otherwise - silence exists in the actions of individuals, mediamaking cultures, and communication infrastructures. The second part of the chapter frames political participation as sociotechnical communication-as intertwined moments of individual expression and technological engagement. Seen in this way, we might reconsider contemporary, sociotechnical silences as legitimate forms of political participation that exist alongside more visible, marketplace models of communicative self-governance that tend to focus on the production and circulation of speech.

\section{The Presence of Absence}

Before examining absence as a sociotechnical phenomenon, it is worth reviewing different ways that absence has appeared historically in different forms of political participation and association.

For example, conscientious objectors purposefully violate the law motivated by the belief that they are "morally prohibited to follow the law because the law is either bad or wrong." (Brownlee, 2013, n.p.) When in the context of refusing to obey a law, examples include draft dodging or refusal to pay taxes; or absence may surface in objections against court directives, such as Jehovah's Witnesses opting out of saluting a flag. The key dimension of conscientiously refusing a law or legal directive-versus conscientiously evading the same-is that there is a visible, explicit declaration of the refusal's meaning. The absence of compliance appears in a statement or behavior, either as an individual action or as a coordinated, collective refusal (Brownlee, 2013; Raz, 1979). The entire point of such absences and refusals is that they are concrete and visible counterforces designed to visibly resist dominant forms of power and rally others into conscientious objection.

Another type of political absence exists as associational invisibility or selfisolation. Catherine Squires (2002) describes the creation and sustenance of black "enclave publics" by abolitionists and slaves in the US South who needed privacy and seclusion to develop secure systems of communication. 
to tightly control their visibility and legibility in order to foster strategic communities of resistance that could ensure solidarity and minimize debate. And she further discovered "satellite publics" created by, for example, the Nation of Islam, to purposefully avoid inclusion in wider debates that they saw as incompatible with the threats of violence and civil disruption that they advocated. In each case, these publics used strategic invisibility and isolation to create memberships and associations, and achieve specific forms of social change. What seemed like silence, invisibility, or isolation was actually strategically and selectively (in)visible participatory politics.

Absence can also appear in voting behaviors. Adopting an economic model of participation and information, Downs (1957) suggests that people may rationally choose to be ignorant because the "saving a consumer could make by becoming informed about how government policy affects any one product he purchases simply does not recompense him for the cost of informing himself-particularly since his personal influence on government policy would probably be slight" (p. 149). ${ }^{1}$ Schumpeter similarly anticipated the high cost of navigating surfeits of political information, suggesting that nonvoting was an understandably apathetic response to an environment that was simply too complex to navigate and that individuals stood a small chance of influencing. It made sense not to participate. A lack of voting and broader political participation can also be read as trust in governing elites, involuntary structural exclusion (e.g., based on race, gender, or class), oppressive voter registration requirements, the absence of a mobilizing community, a perceived lack of relevance of political life and parties, and skepticism about the efficacy of participation (DeLuca, 1995; Held, 2006). Even the visibility of voting and campaigning has changed. Voting first appeared as vocal, public pronouncements, then moved to secret ballots (Schudson, 1998), and now is ambivalently signaled through "I Voted" stickers and Facebook badges as well as rules barring campaign activities around polling places and prohibitions on photographing ballots. As DeLuca (1995) and Eliasoph (1998) show, entire models of power and politics can be developed by tracing the absence of voting, antipathy toward political action, or retreat from civic communication. Indeed, as Wells et al. (2017) found, there came a point during the recall of Wisconsin governor Scott Walker when "many citizens found it impossible to continue political discussion ... call[ing] into question the ability of talk to bridge political and social differences in periods of polarization and fragmentation." (p. 131)

Conscientious objection, enclave publics, and voting abstentions are largely voluntary forms of absence-people choose to opt out of a political 
regime, association, representation, or electoral process. But there are also involuntary political absences. Most obviously, people can be disenfranchised, as was the case in many Western democracies that long disallowed voting by anyone but white, landowning males. At various points in the history of national censuses (M. J. Anderson, 2015), survey techniques (Igo, 2007), and information archiving (Carter, 2006), the creation, deletion, and wording of bureaucratic categories effectively erased many people's identities, histories, and demographics from official public records. They were involuntarily made invisible from information systems and not counted as political constituencies (B. Anderson, 1983). In these cases, absences and silences were not evidence of rational ignorance, conscientious protest, or strategic self-isolation. They were officially sanctioned erasures that showed who had the power to define, categorize, and include - a kind of "associational suppression" that created political constituencies and set the terms of political participation. ${ }^{2}$

This kind of structural, associational suppression appears in Gangadharan's account of digital exclusion elsewhere in this volume. With contemporary Detroit's socioeconomic transformations as her backdrop, she argues that instead of seeing digital exclusion as simply a lack of broadband connectivity - a problem to be overcome with more technology-the online invisibility of marginalized groups is actually evidence of more complex exclusionary dynamics. Through "internal exclusion" processes, even though "marginalized people might be able to access the internet or successfully adopt broadband ... a combination of socioeconomic factors interferes with their ability to use broadband and participate meaningfully in internet culture," as Gangadharan points out earlier in this volume. Their ways of communicating are not supported, their concerns are minimized, their associations are not represented. They may have broadband connections, devices, and accounts, but their presence is always potential—or a small fraction of what it could be-because their inclusion is narrowly defined as technology access, not communicative power. Their invisibility and suppression can never fully be redressed in purely technological images of connectivity.

Although such absences have different motivations and forms, they share orientations to agency and structure, often best explainable as structuration: agency is not an inalienable feature of an individual but rather a set of dynamic forces that create an individual "capacity for agency" out of intertwined social structures, cognitive schemas, and organizational resources (Giddens, 1984; Sewell, 1992). We might see absence similarly. There is both an individual capacity to make absences and an inescapable experience of having absences imposed upon you. Some absences emerge from individual 
choices not to participate, such as calculating that participation is simply irrelevant or not worth the effort. Others come from institutions and broader structural forces: voting policies that exclude, political parties that devalue constituents, ballots that must be secret, and campaigning that is barred at certain times and places.

In an age when much political participation happens through digital communication systems, how should we think about the voluntary and involuntary dynamics of absence?

Before moving on to a broader discussion of how publics and public participation can be seen through intertwined social and technological absences, it is worth looking closely at how digital communication systems create silences. As much as digital materials, objects, and infrastructures can be ways of tracing political power (e.g., how data create identities, how algorithms structure choices, how platforms moderate content), they can also be read for absences: moments when people, places, and perspectives are not rendered in information infrastructures, do not take visible or recognizable forms, or are hidden from or silenced within public discussions. I elsewhere call this a "whitespace press" (Ananny, 2017) in which a mix of journalistic practices, traditions, institutions, and digital infrastructures - explicitly and implicitly, intentionally and unintentionally — create absences. Such absenceseverything from pauses in interviews and uncovered topics to outright censorship and algorithmically blocked content-are not simply failures to speak but are, most broadly, opportunities to rethink the meaning and form of political participation in digital communication contexts.

Such absence is a type of participation and political communication that can best be understood by tracing how human and computational power work together. These sociotechnical absences can appear as individual actions (behaviors, devices, and choices of media audiences and technology users), decisions by communication creators (journalists who create news and social media platform designers who create the conditions under which news circulates and is interpreted), and infrastructural dynamics (largely invisible intersections of semi-autonomous technologies, design assumptions, and relational databases that regulate how information is produced and made visible). At each site, we might consider the work behind these sociotechnical absences and ask what they mean for communicative self-governance and political participation.

In the following three sections I examine these sociotechnical absences and, using examples, consider the role that each plays in structuring contemporary, networked, digital political participation. 
I N D I V I D U A L B E H A VIOR S

Some sociotechnical silences are created because people disconnect from technology, isolate themselves from communication systems, and seek out media-free spaces. Such absences can take a variety of forms. Approximately 70 percent of Americans report some kind of "news fatigue" (Gottfried \& Barthel, 2018), and many report complex feelings of exhilaration, guilt, and relapse when they abandon and return to social media technologies (Baumer, Guha, Quan, Mimno, \& Gay, 2015). There is a growing community of reformed technologists calling on technology companies to fix the addictive qualities of their products (Lewis, 2017); device makers are beginning to help people limit technology through designs that create pauses and "media prophylaxis" that anticipates and ameliorates the harms of addiction (Mulvin, 2018); and scholars are increasingly following the suggestions of early internet researchers (Oudshoorn \& Pinch, 2003; Wyatt, Thomas, \& Terranova, 2002) to map the complex history and phenomenology of individuals' technology avoidance, reuptake, and addiction (Baumer, Ames, Burrell, Brubaker, \& Dourish, 2015; Plaut, 2015).

The very communication spaces and content that ostensibly help rich democratic self-governance thrive are targets of nonuse. Some young people avoid in-depth engagements with news, instead seeking out "functional information alternatives" to headlines they see and topics they see journalists covering; for example, instead of reading news stories about international affairs that headlines tell them are relevant and timely, they might instead watch a television show or movie on a similar topic or read a Wikipedia page about the relevant area (Edgerly, 2016). Often called "media sabbaticals," these can be triggered by "message fatigue" and a desire to avoid persuasive environments (So, Kim, \& Cohen, 2016) and news contexts altogether (Ksiazek, Malthouse, \& Webster, 2010). And such news avoidance is gendered, with working- and middle-class women often reporting that "news is for men," that divisions of labor within their households leave them with less time to consume news, and that the care work they are disproportionately responsible for harms their ability to keep up with news that is often seen as negative or depressing (Toff \& Palmer, 2018). Women may be less likely to appear in surveys of news audiences because news as a genre is incompatible with highly gendered work and home environments.

Recent work also finds that a fear of online social isolation - of saying the wrong thing and finding oneself banished from Facebook spaces (Chan, 2017), or talking about topics thought to be too politically sensitive (Hamp- 
ton et al., 2014)—drives people to self-censor, retreat from online forums, seek out positive expressions, and create entirely new "spiral of silence" dynamics that make them less likely to speak if they think their opinions are in the minority or are soon to be (Askay, 2015; Soffer \& Gordoni, 2017). In the aftermath of Trump's election, Philippa Lockwood told the Guardian:

Immediately after the election, I had to take a break from social media. These days, I'm back on, but making an effort to focus my time on positive people and reputable, newsworthy posts. As counter-productive as this may seem, I'm also surrounding myself with people who share my liberal political beliefs, who see the value in immigrants, who believe in women's rights, etc. I know we're supposed to be 'bursting our political bubbles', but I find it more rewarding to share with likeminded souls, and use our time and energy to mobilize those like us to shake things up in the next election cycle. (Eberspacher \& Guardian Readers, 2017)

Other more seemingly trivial examples illustrate the extent to which individuals are creating or choosing low- or no-media environments. People are increasingly asking for and patronizing gym facilities that ban cable news from its televisions; Life Time Fitness removed CNN, Fox News, MSNBC and CNBC from all of its 128 gyms in the United States and Canada (Schmidt, 2018). People engage in a wide variety of selective avoidance techniques online, unfollowing, unfriending, and blocking people they disagree with, especially during times of acute political conflict (Bode, 2016; John \& Dvir-Gvirsman, 2015; Zhu, Skoric, \& Shen, 2017)—although a federal judge recently ruled that such blocking by Trump and other public officials unconstitutionally sequesters them from the publics they are meant to hear (Herrman \& Savage, 2018). Finally, Disconnect magazine (Ingram, 2018) is an online publication that is free only to readers who disconnect their devices from the internet-it simply fails to load until people disable the WiFi on their laptops, phones, or tablets, demanding that people give the magazine their entire attention, effectively banishing multitasking and other forms of mediated interactivity while reading.

Idiosyncratic and fun, deeply structural and politically grave, these are new sociotechnical spaces of absence. From news avoidance and technology sabbaticals to self-censorship and selective exposure, new forms of demediation give individuals a great deal of power to tailor their media environments. Such absences are related to, but distinct from, personalized echo chambers and algorithmic filter bubbles - they are, instead, spaces of silence through which people can make themselves unreachable. 
ME D I A - M A K I N G C U L T URE S

A second type of sociotechnical absence centers on cultures of professionalized media making. These are populated and defined by a broad set of actors I call "communication creators": professional producers who create online content (e.g., journalists who write stories for mainstream news outlets, advertisers who create messages) and designers who create conditions under which online content circulates and is interpreted (e.g., user experience and news-feed algorithm designers at Facebook or Google). In the traditions, practices, and cultures of such creators and designers, we can see the formalization and normalization of decisions about what not to show, what not to algorithmically surface.

In her study of journalists' engagements with online troll communities, hate groups, and disinformation networks, Phillips (2018) found that the "choices reporters and editors make about what to cover and how to cover it play a key part in regulating the amount of oxygen supplied to the falsehoods, antagonisms, and manipulations that threaten to overrun the contemporary media ecosystem" (p. 2). This question of whether to oxygenate or suffocate such harmful content played out as professional dilemmas in which journalists expressed deep ambivalence: covering such communities may increase their popularity and harmfulness of them and their tactics, but ignoring them makes it possible for worse actors to take their place, gives the impression that such speech is acceptable, and misses an opportunity to educate audiences and mobilize counterpublics. More recently, journalists have also debate whether to report on Trump's tweets at all, fearing that they are fueling the visibility of material that actually works against a free press (Pope, 2017) — a dilemma about whether journalists should always cover a president's communication or whether they should refuse to cover material that they think harms the public. ${ }^{3}$

Some news organizations also look critically at what kind of sources are systematically absent from their coverage. For example, a strong gender bias that runs throughout journalistic practices that routinely silence women: on Twitter, journalists primarily follow and retweet men, soliciting them as sources for stories and story ideas; and on Wikipedia (a source that many journalists routinely draw upon for background research and authoritative sources), the vast majority of contributors and editors are men. Men are the primary online speakers that journalists are listening to and quoting; because women are not speaking or being listened to on these platforms, they often fail to appear in online journalists' stories (Matias, Szalavitz, \& Zuckerman, 
2017; Usher, Holcomb, \& Littman, 2018). Spurred on by this research, popular Twitter hashtags like \#WomenAlsoKnow, and the observation that, on average, only 21 percent of the people it was quoting were women, the Financial Times recently tried to curb its gender biases by creating a computer program to monitor the gender patterns in its sources' names and alert senior editors if they were systematically underquoting women.

Sometimes, though, news organizations explicitly try to silence sources and limit audience participation. The Los Angeles Times does not allow letters to the editor that deny the human role in climate change (Thornton, 2013); Popular Science discontinued comments on many of its stories after experimenters found that people who read stories with comments actually learned less about science and technology than they did in stories without comments (LaBarre, 2013) because their viewpoints became so polarized (A. A. Anderson, Brossard, Scheufele, Xenos, \& Ladwig, 2013); and the Atlantic recently discontinued online comments on most of its stories, instead reverting to the older, curated letters-to-the-editor format (Goldberg, 2018). The overarching logic is that sometimes, according a journalists' own conceptions of what publics need, some voices need to be silenced and some topics need to be limited.

Facebook faces similar dilemmas in designing its content moderation strategies and battling misinformation at the size, scope, and speed its platform demands. Should it expose its users to potentially false and harmful information, letting them see a full range of claims and counterclaims, rarely censoring content or silencing speakers? The social psychology-much less its operationalization in interface design - is not yet settled on whether people benefit from seeing counterclaims, contextualizing misinformation, or being insulated entirely from content judged erroneous (Bode \& Vraga, 2015; M. Karlsson, Clerwall, \& Nord, 2014; M. Karlsson, Clerwall, \& Nord, 2016; Lewandowsky, Ecker, Seifert, Schwarz, \& Cook, 2012; Lyons, 2017). Or, should it take a more aggressive moderation stance on banning content? Such moves can silence actors the company defines as bad-for example, it explicitly banned Russia's Internet Research Agency after public pressure (Stamos, 2018)—but they can also reveal the unworkable scale of its moderation regime, reliance on imperfect algorithms, and the unaccountable nature of its moderation policies (Gillespie, 2018). The opacity and ambiguities of Facebook's moderation systems mean that it routinely bans actors it later decides to be legitimate: journalists (Liptak, 2017), public officials (Scott \& Isaac, 2016), activists (Levin, 2016), anthropologists (Alexander, 2016), and entire racial groups (Angwin \& Grassegger, 2017). Facebook silences come in the form of one-off bans, policy implementations, and false-positive accidentsnone of which is governed by formal public accountability mechanisms, but 
all of which have an impact on which content is seen or unseen on the world's largest social media platform.

Other choices by communication creators may seem tangential or unrelated to the idea of political participation but they suggest other, related domains of absence in authorship and design, and portend the power that content creators and technologists have to influence what kind of media can be seen or erased. For example, advertisers can effectively influence which online content is financially viable when they set the terms under which they allow their advertisements to be seen alongside news content: some will avoid stories with what they see as controversial keywords, others refuse to have their ads appear near user comments to appear alongside controversial stories, and still others refuse to appear on certain news sites altogether (Dwoskin \& Timberg, 2017; Vranica, 2017).

And technology can be a playful arbiter of scarcity. Impossible Labs recently experimented with producing a "limited edition digital book": only one hundred people can own the original, but before any owner can transfer ownership to other person, she must "remove two words and add one to every page," meaning that "frankly, after 20 owners it will be unreadable" (Stinson, 2017).

These sites and practices all point to an emerging domain of content production and platform design characterized by a concern with absence: when to create it, what professional and public rationales underpin its existence, who will be excluded, and how to mix computational and curatorial systems in its production.

I NFRASTRUCT URAL DYNAMICS

Absences are also created through a mix of infrastructural forces that control the visibility and unseen nature of media. By "infrastructure," I mean Susan Leigh Star's and Karen Ruhleder's model of artifacts, practices, and values that are embedded in sociotechnical structures, standardized, largely invisible, intertwined with expertise, inseparable from individuals' perspectives, learned through communities of practice, and extended in space and time beyond single occurrences (Star \& Ruhleder, 1996). The presence and power of such infrastructures are often seen only when they break down or when analysts engage in what Bowker and Star (1999) call "infrastructural inversion": surfacing the unseen, invisible work that always entails a mix of hidden artifacts and de-emphasized and often gendered labor (Shapin, 1989; Star \& Strauss, 1999).

In contemporary media spaces, such infrastructural dynamics play out in 
a number of ways. One of these centers on ways that "big data" systems are designed to make some people more visible than others - to implicitly enroll certain people as constituents of data-based publics while effectively ignoring the existence of others. For example, in his critique of the idea that public information systems predicated on "big data" offer more egalitarian access to public goods and services, Lerman (2013) shows how the information of many people "is not regularly collected or analyzed, because they do not routinely engage in activities that big data is designed to capture. Consequently, their preferences and needs risk being routinely ignored when governments and private industry use big data and advanced analytics to shape public policy and the marketplace" (p. 55). He goes on to construct a hypothetical but plausible persona of a person who will never appear in the data sets used to model and optimize public transit: "He lives two hours southwest of Manhattan, in Camden, New Jersey, America's poorest city. He is underemployed, working part-time at a restaurant, paid under the table in cash. He has no cell phone, no computer, no cable. He rarely travels and has no passport, car, or GPS. He uses the Internet, but only at the local library on public terminals. When he rides the bus, he pays the fare in cash." But it is not the right answer to simply equip low-income people with such technologies and make sure that they are included in public data systems. This point is taken up by Gangadharan (2012), who notes that when "chronically underserved communities"- poor people, communities of color, indigenous, and migrants - are included in online data sets, through broadband inclusion initiatives, they become more vulnerable to surveillance and privacy infringements. That is, making chronically underserved communities more visible online actually disproportionally exposes them to profiling and persuasion techniques that further drive their disempowerment. It may make more sense for such groups to avoid broadband inclusion initiatives and the "opportunities" they afford, if the privacy costs are too high. Paradoxically and tragically, it may actually be in the self-interests of disempowered groups to continue being invisible to such infrastructures - to avoid being enrolled in data publics.

Such concerns about privacy and visibility also play out more broadly for all platform users. For example, through its Pixel technology, Facebook tracks web users and includes their behavioral analytics in its advertising models, regardless of whether they have a Facebook profile (Brandom, 2018). There is, effectively, no opting out of participating in Facebook's data profiling.

Infrastructural visibility can also appear in the design and deployment of communication infrastructures. For example, placing a seemingly simple piece of code on a web server - a file named "robots.txt" - renders that server 
invisible to search engine crawlers like Google. A mix of social and technological protocols (Elmer, 2008) - by convention, crawlers are understood to ignore servers with this file and thus render them invisible in indexeseffectively creates a shadow layer of online content that is effectively inaccessible to search-engine users.

Other types of invisibility are embedded within an online community's technology. For example, the software development community GitHub recently introduced a "cooling off" period as a way of helping people take a break when online interactions become heated: "sometimes a solution can't be reached until everyone has had time to cool down. Now, with interaction limits, maintainers can temporarily limit who can comment, create pull requests, and open issues among existing users, collaborators, and prior contributors. After 24 hours, limits expire and allow users to go back to participating in the conversation" (Bieda, 2017, n.p.). And, seemingly inspired by a Habermasian ideal of bracketing reputations in communication contexts and a desire to experience analytics-free social media, artist Benjamin Grosser created Demetricator: a browser plug-in for Facebook and Twitter that "removes all visible metrics from the platform" (Zweig, 2018, n.p.). When installed, the plug-in lets users see Facebook and Twitter profiles as they normally would but removes all numeric indicators of popularity and scale - tallies of likes, retweets, friends, followers are all erased. This is a kind of reputational whitespace, an attempt to focus conditions of participation on the content of messages rather than the quantitatively perceived authority of the messengers.

A final dimension of infrastructural absence relates to the often-invisible nature of the labor required to maintain and repair digital communication platforms that are often perceived as algorithmic, automated, and largely the product of computational processes that require little human involvement. In fact, much of the seeming consistency of online life is thanks to a large set of often unseen laborers: for example, the "microworkers" of Amazon's Mechanical Turk underpinning many artificial intelligence training systems and much academic research (Irani, 2015a), the human attendants who turned pages for Google's supposedly automatic book scanners (Irani, 2015b), and the vast armies of commercial content moderators who must quickly - they often only have a few seconds - review psychologically and emotionally taxing content, and apply technology companies' often-vague censorship policies (Roberts, 2016). The machinery of online participation may seem like it offers endless opportunities for everyone to express themselves and build community through communication, but such associational life rests upon a vast and often invisible infrastructure of human labor. 


\section{Participation as Sociotechnical Action}

Although much scholarship has traditionally seen political participation in voting behaviors, civic associations, political campaigns, media forums, fan cultures, and many other settings, it can also be seen as a sociotechnical system that regulates the (in)visibility of expression. Today, those sociotechnical forces and communicative phenomena live in social media platforms, information algorithms, relational databases, and artificial intelligence systems. What might absences in these systems and structures mean, and how we might see a seeming lack of media representations not as a failure to participate but as evidence of political participation based on listening, observation, purposeful retreat, and interpretations of relevance?

Participation is a kind of sociotechnical action that plays out in associations and relationships among humans and nonhumans, people and artifacts. Just as the materiality of digital spaces is different from that of traditionally, face-to-face, physical spaces, so, too, are the material dimensions of digitally mediated political participation. Part of that materiality entails asking what a lack of materiality means: When do people and ideas not appear in online groups? How might their absences be explained not by apathy or exclusion, but by an assemblage of human and nonhuman actors? As people's contemporary communication is increasingly intertwined with computational devices and platforms, how might their absences be understood as functions of how they feel about those objects and spaces? When someone leaves Facebook - or fails to show up through a mix of personal choice and algorithmic exclusion-do they also leave a political constituency, a set of people who are similarly choose to be or are made invisible and silent?

Although the term participation is central to much of democratic theory, it is still highly contingent and debatable in both form and aims. It means different things in different contexts, often presumes different democratic ideals, and carries with it different assumptions about what role individual and collective actions play in democratic institutions.

The literature on democratic participation - its meanings, debates, deployments - is too vast to be summarized here, but it is worth briefly sketching a few of its dimensions. As Kelty (2017) outlines in his "Grammar of Participation," the term arguably making one of its first and most significant contemporary appearances in the 1962 Port Huron Statement, spurring a burst of scholarship. The idea has variously been seen as the central concept in democratic theory (Held, 2006; Pateman, 1970); a precondition and product of deliberative democracy (Fishkin, 1991); a key dynamics in creating democratic polities through associational life and civic volunteerism (Fung, 
2003; Putnam, 1993; Verba, Schlozman, \& Brady, 1995); evidence of the validity of elections and legitimacy of different forms of representative government (Held, 2006), public opinion measurements (Page \& Shapiro, 1992; Salmon \& Glasser, 1995), and journalistic practices (Glasser, 1999). Finally, cultural studies scholars have critiqued assumptions about participation to draw attention to forms of popular culture, individual expression, and socially organized participation that have political power and significance but have been historically absent from political theory's dominant models of political participation (Hall, 1992; Jenkins, 1992; Williams, 1983). Such participation is variously as evidence of an engaged and legitimate populace, as a literacy to be taught, and as a source of discontent that elites need to manage.

Absences also take material form in other less explicitly political domains that nonetheless are crucial to association making. Rooted in cultural studies' call for broader and subaltern models of political participation (Jenkins, 2006), urban planning's development of participatory professional practices (Forester, 1993; Schön, 1992), and science and technology scholars' arguments that materials play powerful roles in social settings (Law \& Mol, 1995; Williams, 2006), a newer approach to political participation has more recently appeared that sees objects, infrastructures, and physical settings not just as places where social participation happens or representations of social processes but as actors in their own right that, inseparably intertwined with humans, have political force and a power to shape the meaning of political participation. Most forcefully advanced by Marres (2012), this type of participation "involves the supplanting of the familiar character of the informational citizen'- the one in need of information in order to adequately perform his role of opinionated, decision-making subject - with another figure, which we could call the material public" (pp. 4-5). Marres and her model of material publics is deeply rooted in American pragmatism and, in particular, John Dewey's image of a public as the "conversion of . . . associated behavior into a community of action, saturated and regulated by mutual interest in shared meanings, consequences that are translated into ideas and desired objects by means of symbols" (Dewey, 2007, p. 13).

Very much aligned with visions of social life as human-nonhuman intertwining, Marres and Dewey see materiality-objects, symbols, infrastructures - as inseparable from associational life. This inseparability of humans and nonhumans is evidence of precisely the kind of public they aim to explicate: a public predicated not on informational exchange, private action, or individual choice but on the inextricable consequences of having no choice but to share affiliations and physical settings. For scholars of material publics, it makes less sense to think about participation of humans separate from 
their nonhuman companions; it makes more sense to try to identify intertwined conditions and consequences that arise from their collective, joint participation.

For example, in his study of the Baku-Tbilisi-Ceyhan pipeline, Barry (2013) finds the "affected public" to be not only a geographic or administrative constituency-people who live in a particular place represented by a certain government - but also a material polity defined by their proximity to the pipeline, scientific opinions about the environmental impact of pipeline proximity, economic incentives to produce and transport different volumes of oil, and expert projections about the future significance of the pipeline. For Barry, the pipeline - its route, its physical properties, its history, its projected behavior-participates: it is a constituent in the story of associational life and it plays a role in convening the inextricable, intertwined consequences that define public life.

In the context of digital, networked communication systems, materiality can take on new meanings. While still rooted in the symbol systems and object-relations Dewey saw as core to public action, digital tangibility suggests that something other than simply symbolic language or physical instantiation is at play. Leonardi (2012) offers some helpful distinctions, defining materiality as digital forms that "endure across differences in place and time and are important to users," sociomateriality as "activities that meld materiality with institutions, norms, discourses," and material agency as "the capacity for nonhuman entities to act absent sustained human intervention" (pp. 3542). Taken together, this typology suggests that digital forms can persist, take on meaning and significance, integrate with human action and socially situated practices, and sometimes achieve a kind of autonomy. In the context of networked, digital communication systems, we might, for example, use this typology to see the material dimensions of data, algorithms, and platformsand their role in the kind of public-making political participation that Dewey and Marres envision.

For example, consider the role that digital databases play in convening publics. In his study of online identity, Cheney-Lippold (2017) chronicles how myriad dimensions of individuals' identities - race, gender, age, orientation, political affiliations - are constantly derived, updated, categorized through a combination of surveillance, disclosure, and statistical prediction. He argues not just identities are social and statistical constructs-this is nothing new (Bouk, 2015; Igo, 2007) — but that some image of a person's identity now exists as computationally calculated categories living in largely unsupervised troves of online traces that are periodically polled and rendered to create digitally material, databased representations of identity that endure 
across times and places, emerge from people's actions and shape the options available to them, and act at semiautonomous scales that resist close scrutiny. Most radically, Cheney-Lippold (2017) argues that we are these data; they are not superfluous to our political identities or actions. We are intertwined with the systems that make these digital materials in the same way that Dewey and Marres see publics as people who are inextricably linked via social conditions that are largely beyond their individual control. The material publics that emerge are inseparable from infrastructures of databased identity, making it impossible to ask questions about political standing, association, and agency without considering the construction, assumptions, and power of these database infrastructures.

Algorithms and platforms show evidence a similar materiality. To the extent that algorithms are not just computer code but are institutionally embedded, semiautonomous, computational logics that sustain often inscrutable relationships between people and data (Ananny, 2016; Bucher, 2018), they, too, serve as digital materials of public life. As Gillespie (2014) asserts, they "not only help us find information, they provide a means to know what there is to know and how to know it, to participate in social and political discourse, and to familiarize ourselves with the publics in which we participate" (p. 167). Social media platforms serve similar, and closely aligned public, material functions to data and algorithms. Although platforms do not make content, "they make important choices about that content: what they will distribute and to whom, how they will connect users and broker their interactions, and what they will refuse." (Gillespie, 2017, p. 254) Unlike the common carriage logics of post offices and telecommunication lines, and despite claims to neutrality, platforms have interests (Gillespie, 2018; McKelvey, 2014) - interests that take material form in the moderation policies, algorithmic systems, terms of service, and user experience designs. Indeed, platforms articulate a kind of double public (Langlois, Elmer, McKelvey, \& Devereaux, 2009): they are not only digital places where people convene to discover, debate, and coordinate action about their shared social conditions; the governance of platforms themselves is hotly contested and susceptible to extreme power differentials as users often lack knowledge about how exactly platforms shape their communicative practices and lack the agency to leave platforms and recreate their relationships and data elsewhere (Baumer et al., 2013; Portwood-Stacer, 2013).

If the political significance of participation is intertwined with the institutions and material systems that enable individual and collective action, and if these systems in turn are not only linguistic and representational but also material, infrastructural, and digital, then appreciating the different mean- 
ings of contemporary political participation means delving more deeply into the details of digital materiality.

\section{Conclusion}

Though incomplete and idiosyncratic, this tour of sociotechnical absences and their political significance was meant to offer new ways of thinking about contemporary, digital, communicative forms of political participation.

Designers and advocates of many communication systems tend to assume that marketplaces of speech are the most effective and equitable ways of achieving communicative self-governance. More speech is always better, more participation will fix political problems, more voices will produce a greater variety of solutions. In many cases this is true, and such marketplaces are democratically essential. But as I have tried to argue, there is another side to communicative self-governance that might take into account the role of silences and absences. Feminist scholars have long argued that seemingly invisible - and often gendered-forms of participation like listening are essential to the health of communicative self-governance. Instead of simply equating public participation with public speaking, we might additionally consider how "listening publics" (Lacey, 2013) might be recognized and nurtured by designing for and valuing silences that are not really absences at all but rather spaces for listening (Bickford, 1996). Such an imperative has political importance because, as Dryzek (2002) writes "the most effective and insidious way to silence others in politics is a refusal to listen" (p. 149). Democracy cannot work if everyone is speaking and no one is listening.

Today and in online contexts, these absences, silences, and invisibilities appear in sociotechnical infrastructures that are often privately controlled, opaque, inscrutable, unaccountable, and driven by economic and advertising logics that value, above all else, more content and networks with more links. Surveillance, profiling, and targeted advertisements do not work very well if people are silent, absent, listening.

And many people, in turn, fear being invisible to such algorithmic systems (Bucher, 2012). If newsfeed algorithms do not see you and your perspectives, if public systems are only designed for those who leave data traces, and if artificial intelligence systems are trained without your data-you run the risk of being invisible without agency. You have not chosen to be invisible or a contemplative listener-you have, instead, been erased as a participant, excluded from a constituency. Such exclusion is very different from taking a "news sabbatical." Indeed, in many ways, being absent is a privilege. If you 
have the option to rejoin a system at any time and pick up where your silence began, or if you have a trusted and powerful cohort able to represent your interests, the significance of your absences is very different from those who cannot easily slip in and out of polities as their preferences and desires dictate.

The onus is on analysts and creators of contemporary political participation to see absences, to ask who is not present in any given constituency, and to recognize that silences, absences, and exclusions can emerge from a mix of individual behaviors, professional practices, and infrastructural forces. By no means am I arguing that people should be silenced or that silence is a greater form of political participation than speaking. Rather, my hope is that scholars and designers of contemporary, networked political participation see the value of looking for things that don't seem to be there.

\section{Notes}

1. For a good overview of agnotology, the emerging field on the sociology of ignorance, see Abbott (2010); Croissant (2014); McGoey (2012); Proctor (2008).

2. Many thanks to Lucy Bernholz for this phrase and concept, which I have tried to do justice to here.

3. I explore more of these journalistic dilemmas of white space in greater detail in Ananny (2017).

\section{References}

Abbott, A. (2010). Varieties of ignorance. American Sociologist, 41(2), 174-189. https://doi.org/ 10.1007/s12108-010-9094-x

Agre, P. E. (2002). Real-time politics: The internet and the political process Information Society, 18(5), 311-331.

Alexander, L. (2016, March 23). Facebook's censorship of Aboriginal bodies raises troubling ideas of "decency." The Guardian. Retrieved from https://www.theguardian.com/technology/ 2016/mar/23/facebook-censorship-topless-aboriginal-women

Ananny, M. (2016). Toward an ethics of algorithms: Convening, observation, probability, and timeliness. Science, Technology \& Human Values, 41(1), 93-117. https://doi.org/10.1177/ 0162243915606523

Ananny, M. (2017). The whitespace press: Designing meaningful absences into networked news. In P. J. Boczkowski \& C. W. Anderson (Eds.), Remaking the news (pp. 129-146). Cambridge, MA: MIT Press.

Anderson, A. A., Brossard, D., Scheufele, D. A., Xenos, M. A., \& Ladwig, P. (2013). Crude comments and concern: Online incivility's effect on risk perceptions of emerging technologies. Journal of Computer-Mediated Communication. https://doi.org/10.1111/jcc4.12009

Anderson, B. (1983). Imagined communities (Rev. ed.). London, UK: Verso.

Anderson, M. J. (2015). The American census: A social history (2nd ed.). New Haven, CT: Yale University Press.

Angwin, J., \& Grassegger, H. (2017, June 28). Facebook's secret censorship rules protect white 
men from hate speech but not black children. ProPublica. Retrieved from https://www .propublica.org/article/facebook-hate-speech-censorship-internal-documents-algorithms

Askay, D. A. (2015). Silence in the crowd: The spiral of silence contributing to the positive bias of opinions in an online review system. New Media \& Society, 17(11), 1811-1829. https://doi .org/10.1177/1461444814535190

Baker, C. E. (2002). Media, markets, and democracy. Cambridge, UK: Cambridge University Press. Barber, B. R. (2004). Which technology and which democracy? In H. Jenkins \& D. Thorburn (Eds.), Democracy and new media (pp. 33-48). Cambridge, MA: MIT Press.

Barry, A. (2013). Material politics: Disputes along the pipeline New York, NY: Wiley-Blackwell.

Baumer, E. P. S., Adams, P., Khovanskaya, V. D., Liao, T. C., Smith, M. E., Sosik, V. S., \& Williams, K. (2013). Limiting, leaving, and (re)lapsing: An exploration of Facebook non-use practices and experiences. Paper presented at the Proceedings of the SIGCHI Conference on $\mathrm{Hu}$ man Factors in Computing Systems, Paris, France.

Baumer, E. P. S., Ames, M. G., Burrell, J., Brubaker, J. R., \& Dourish, P. (2015). Why study technology non-use? First Monday, 2o(11). Retrieved from http://firstmonday.org/ojs/index .php/fm/article/view/6310/5137

Baumer, E. P. S., Guha, S., Quan, E., Mimno, D., \& Gay, G. K. (2015). Missing photos, suffering withdrawal, or finding freedom? How experiences of social media non-use influence the likelihood of reversion. Social Media + Society, 1(2). https://doi.org/10.1177/ 2056305115614851

Benkler, Y. (2003). Freedom in the commons: Towards a political economy of information. Duke Law Journal, 52, 1245-1276.

Benkler, Y. (2006). The wealth of networks: How social production transforms markets and freedom. New Haven, CT: Yale University Press.

Bickford, S. (1996). The dissonance of democracy: Listening, conflict, and citizenship. Ithaca, NY: Cornell University Press.

Bieda, L. (2017, May 30). Introducing temporary interaction limits. GitHub Blog. Retrieved from https://blog.github.com/2017-05-30-introducing-temporary-interaction-limits /

Bishop, J. (2007). Increasing participation in online communities: A framework for humancomputer interaction. Computers in Human Behavior, 23(4), 1881-1893. https://doi.org/10 .1016/j.chb.2005.11.004

Bode, L. (2016). Pruning the news feed: Unfriending and unfollowing political content on social media. Research \& Politics, 3(3), art. 2053168016661873. https://doi.org/10.1177/ 2053168016661873

Bode, L., \& Vraga, E. K. (2015). In related news, that was wrong: The correction of misinformation through related stories functionality in social media. Journal of Communication, 65(4), 619-638. https://doi.org/10.1111/jcom.12166

Bouk, D. (2015). How our days became numbered: Risk and the rise of the statistical individual. Chicago, IL: University of Chicago Press.

Bowker, G. C., \& Star, S. L. (1999). Sorting things out: Classification and its consequences. Cambridge, MA: MIT Press.

Brandom, R. (2018, April 11). Shadow profiles are the biggest flaw in Facebook's privacy defense. The Verge. Retrieved from https://www.theverge.com/2018/4/11/17225482/facebook -shadow-profiles-zuckerberg-congress-data-privacy San Francisco, CA: City Lights. 
Brownlee, K. (2013, December 20). Civil disobedience. Stanford Encyclopedia of Philosophy. Retrieved from https://plato.stanford.edu/entries/civil-disobedience/

Bucher, T. (2012). Want to be on top? Algorithmic power and the threat of invisibility on Facebook. New Media \& Society, 14(7), 1164-1180.

Bucher, T. (2018). If . . then: Algorithmic power and politics. Oxford, UK: Oxford University Press.

Carter, R. G. S. (2006). Of things said and unsaid: Power, archival silences, and power in silence. Archivaria, 61, 215-233.

Chan, M. (2017). Reluctance to talk about politics in face-to-face and Facebook settings: Examining the impact of fear of isolation, willingness to self-censor, and peer network characteristics. Mass Communication and Society. https://doi.org/10.1080/15205436.2017.1358819

Cheney-Lippold, J. (2017). We are data: Algorithms and the making of our digital selves. New York, NY: NYU Press.

Croissant, J. L. (2014). Agnotology: Ignorance and absence or towards a sociology of things that aren't there. Social Epistemology, 28(1), 4-25. https://doi.org/10.1080/02691728.2013.862880

Dahlberg, L. (2001). Computer-mediated communication and the public sphere: A critical analysis. Journal of Computer Mediated Communication, 7(1).

DeLuca, T. (1995). The two faces of political apathy. Philadelphia, PA: Temple University Press.

Dewey, J. (2007). Search for the great community. Kettering Review, 26(2), 9-18.

Downs, A. (1957). An economic theory of political action in a democracy. Journal of Political Economy, 65(2), 135-150.

Dryzek, J. S. (2002). Deliberative democracy and beyond: Liberals, critics, contestations. Oxford, UK: Oxford University Press.

Dwoskin, E., \& Timberg, C. (2017, March 24). For advertisers, algorithms can lead to unexpected exposure on sites spewing hate. Washington Post. Retrieved from https://www .washingtonpost.com / business/technology/for-advertisers-algorithms-can-lead-to -unexpected-exposure-on-sites-spewing-hate/2017/03/24/046ac164-043d-11e7-b1e9 -a05d3c21f7cf_story.html

Eberspacher, S., \& Guardian readers. (2017, April 24). Activism, cynicism-and whiskey: How readers are coping with Trump. The Guardian. Retrieved from https://www.theguardian .com/us-news/2017/apr/24/trump-presidency-100-days-coping-activism

Edgerly, S. (2016). Seeking out and avoiding the news media: Young adults' proposed strategies for obtaining current events information. Mass Communication and Society. https://doi .org/10.1080/15205436.2016.1262424

Eliasoph, N. (1998). Avoiding politics: How Americans produce apathy in everyday life. Cambridge, UK: Cambridge University Press.

Elmer, G. (2008). Exclusionary rules? The politics of protocols. In A. Chadwick \& P. N. Howard (Eds.), Routledge handbook of internet politics (pp. 376-383). London, UK: Routledge.

Fishkin, J. S. (1991). Democracy and deliberation: New directions for democratic reform. New Haven, CT: Yale University Press.

Forester, J. (1993). Critical theory, public policy, and planning practice. Albany, NY: State University of New York Press.

Fung, A. (2003). Associations and democracy: Between theories, hopes, and realities. Annual Review of Sociology, 29, 515-539.

Gandy, O. H. (1993). Toward a political economy of personal information. Critical Studies in Mass Communication, 10(1), 70-97. https://doi.org/10.1080/15295039309366849 
Gangadharan, S. P. (2012). Digital inclusion and data profiling. First Monday, 17(5). https://doi .org/10.5210/fm.v17i5.3821

Giddens, A. (1984). The constitution of society: Outline of the theory of structuration. London, UK: Polity Press.

Gillespie, T. (2014). The relevance of algorithms. In T. Gillespie, P. Boczkowski, \& K. A. Foot (Eds.), Media technologies: Essays on communication, materiality, and society (pp. 167-194). Cambridge, MA: MIT Press.

Gillespie, T. (2017). Governance of and by platforms. In J. Burgess, T. Poell, \& A. Marwick (Eds.), SAGE Handbook of Social Media (pp. 254-278). London, UK: Sage.

Gillespie, T. (2018). Custodians of the internet: Platforms, content moderation, and the hidden decisions that shape social media. New Haven, CT: Yale University Press.

Gillmor, D. (2004). We the media: Grassroots journalism by the people, for the people. Sebastopol, CA: O'Reilly Media.

Glasser, T. L. (1999). The idea of public journalism. In T. L. Glasser (Ed.), The idea of public journalism (pp. 3-20). New York, NY: Guilford Press.

Goldberg, J. (2018, February 2). We want to hear from you. The Atlantic. Retrieved from https:// www.theatlantic.com/letters/archive/2018/02/we-want-to-hear-from-you/552170/

Gottfried, J., \& Barthel, M. (2018, June 5). Almost seven-in-ten Americans have news fatigue, more among Republicans. Pew Research Center. Retrieved from http://www.pewresearch.org/ fact-tank/2018/06/05/almost-seven-in-ten-americans-have-news-fatigue-more-among -republicans/

Hall, S. (1992). Cultural studies and its theoretical legacies. In L. Grossberg, C. Nelson, \& P. Treichler (Eds.), Cultural studies (pp. 277-294). New York, NY: Routledge.

Hampton, K., Rainie, L., Lu, W., Dwyer, M., Inyoung, S., \& Purcell, K. (2014, August 26). Social media and the "spiral of silence." Pew Research Internet Project. Retrieved from http://www .pewinternet.org/2014/08/26/social-media-and-the-spiral-of-silence/

Held, D. (2006). Models of democracy (3rd ed.). Stanford, CA: Stanford University Press.

Herrman, J., \& Savage, C. (2018, May 23). Trump's blocking of Twitter users is unconstitutional, judge says. New York Times. Retrieved from https://www.nytimes.com/2018/05/23/ business/media/trump-twitter-block.html

Hindman, M. (2008). The myth of digital democracy. Princeton, NJ: Princeton University Press.

Igo, S. (2007). The averaged American: Surveys, citizens, and the making of a mass public. Cambridge, MA: Harvard University Press.

Ingram, M. (2018, February 26). A new digital magazine forces you to unplug from the internet. Columbia Journalism Review. Retrieved from https://www.cjr.org/innovations/disconnect -magazine-only-works-offline.php

Irani, L. (2015a). The cultural work of microwork. New Media \& Society, 17(5), 720-739. https:// doi.org/10.1177/1461444813511926

Irani, L. (2015b, January 15, 2015). Justice for “data janitors.” Public Books. Retrieved from http:// www.publicbooks.org/nonfiction/justice-for-data-janitors

Jenkins, H. (1992). Textual poachers: Television fans and participatory culture. Oxford, UK: Routledge Press.

Jenkins, H. (2006). Fans, bloggers, and gamers: Exploring participatory culture. New York, NY: New York University Press.

John, N. A., \& Dvir-Gvirsman, S. (2015). “I don't like you any more”: Facebook unfriending by Israelis during the Israel-Gaza conflict of 2014. Journal of Communication, 65(6), 953-974. https://doi.org/10.1111/jcom.12188 
Karlsson, M., Clerwall, C., \& Nord, L. (2014). You ain't seen nothing yet: Transparency's (lack of) effect on source and message credibility. Journalism Studies. https://doi.org/10.1080/ 1461670X.2014.886837

Karlsson, M., Clerwall, C., \& Nord, L. (2016). Do not stand corrected: Transparency and users' attitudes to inaccurate news and corrections in online journalism. Journalism \& Mass Communication Quarterly. https://doi.org/10.1177/1077699016654680

Kelty, C. M. (2017). Too much democracy in all the wrong places: Toward a grammar of participation. Current Anthropology, 58(S15), S77-S9o. https://doi.org/10.1086/688705

Ksiazek, T. B., Malthouse, E. C., \& Webster, J. G. (2010). News-seekers and avoiders: Exploring patterns of total news consumption across media and the relationship to civic participation. Journal of Broadcasting \& Electronic Media, 54(4), 551-568.

LaBarre, S. (2013, September 24). Why we're shutting off our comments. Popular Science. Retrieved from https://www.popsci.com/science/article/2013-09/why-were-shutting-our -comments

Lacey, K. (2013). Listening publics: The politics and experience of listening in the media age. Cambridge, UK: Polity.

Langlois, G., Elmer, G., McKelvey, F., \& Devereaux, Z. (2009). Networked publics: The double articulation of code and politics on Facebook. Canadian Journal of Communication, 34, $415-434$.

Law, J., \& Mol, A. (1995). Notes on materiality and sociality. Sociological Review, 43(2), 274-294.

Leonardi, P. M. (2012). Materiality, sociomateriality, and socio-technical systems: What do these terms mean? How are they related? Do we need them? In P. M. Leonardi, B. A. Nardi, \& J. Kallinikos (Eds.), Materiality and organizing: Social interaction in a technological world (pp. 25-48). Oxford, UK: Oxford University Press.

Lerman, J. (2013). Big data and its exclusions. Stanford Law Review, 66, 55-63.

Levin, S. (2016, September 12). Facebook temporarily blocks Black Lives Matter activist after he posts racist email. The Guardian. Retrieved from https://www.theguardian.com/ technology/2016/sep/12/facebook-blocks-shaun-king-black-lives-matter

Lewandowsky, S., Ecker, U. K. H., Seifert, C. M., Schwarz, N., \& Cook, J. (2012). Misinformation and its correction: Continued influence and successful debiasing. Psychological Science in the Public Interest, 13(3), 106-131. https://doi.org/10.1177/1529100612451018

Lewis, P. (2017, October 6). Our minds can be hijacked: The tech insiders who fear a smartphone dystopia. The Guardian. Retrieved from https://www.theguardian.com/technology/2017/ oct/05/smartphone-addiction-silicon-valley-dystopia

Liptak, A. (2017, May 21). A journalist's account was suspended after he posted allegations of corruption to Facebook. The Verge. Retrieved from https://www.theverge.com/2017/5/21/ 15672666/facebook-matthew-caruana-galizia-allegations-corruption-account-suspended

Lyons, T. (2017, December 20). Replacing disputed flags with related articles. Facebook Newsroom Blog. Retrieved from https://newsroom.fb.com/news/2017/12/news-feed-fyi-updates -in-our-fight-against-misinformation /

Marres, N. (2012). Material participation. London, UK: Palgrave Macmillan.

Matias, J. N., Szalavitz, S., \& Zuckerman, E. (2017). FollowBias: Supporting behavior change toward gender equality by networked gatekeepers on social media. Paper presented at the Proceedings of the 2017 ACM Conference on Computer Supported Cooperative Work and Social Computing, Portland, OR.

McGoey, L. (2012). Strategic unknowns: Towards a sociology of ignorance. Economy and Society, 41(1), 1-16. https://doi.org/10.1080/03085147.2011.637330 
McKelvey, F. (2014). Algorithmic media need democratic methods: Why publics matter to digital media research. Canadian Journal of Communication, 39, 597-613.

Mulvin, D. (2018). Media prophylaxis: Night modes and the politics of preventing harm. Information \& Culture, 53(2), 175-202.

Oudshoorn, N., \& Pinch, T. (2003). How users and non-users matter. In N. Oudshoorn \& T. Pinch (Eds.), How users matter: The co-construction of users and technology (pp. 1-25). Cambridge, MA: MIT Press.

Page, B. I., \& Shapiro, R. Y. (1992). The rational public. Chicago, IL: University of Chicago Press.

Pateman, C. (1970). Participation and democratic theory. Cambridge, UK: Cambridge University Press.

Phillips, W. (2018). The oxygen of amplification: Better practices for reporting on far right extremists, antagonists, and manipulators online. Data \& Society. https://datasociety.net/wp -content/uploads/2018/05/1_PART_1_Oxygen_of_Amplification_DS.pdf

Plaut, E. R. (2015). Technologies of avoidance: The swear jar and the cell phone. First Monday, 2o(11). http://dx.doi.org/10.5210/fm.v20i11.6295

Pope, K. (2017, July 5). What we miss when we obsess over Trump's tweets. Columbia Journalism Review. Retrieved from https://www.cjr.org/covering_trump/trump_tweets_press _journalists.php

Portwood-Stacer, L. (2013). Media refusal and conspicuous non-consumption: The performative and political dimensions of Facebook abstention. New Media \& Society, 15(7), 10411057. https://doi.org/10.1177/1461444812465139

Preece, J., Nonnecke, B., \& Andrews, D. (2004). The top five reasons for lurking: Improving community experiences for everyone. Computers in Human Behavior, 2o(2), 201-223. https://doi.org/10.1016/j.chb.2003.10.015

Proctor, R. N. (2008). Agnotology: A missing term to describe the cultural production of ignorance (and its study). In R. Proctor \& L. Schiebinger (Eds.), Agnotology: The making and unmaking of ignorance (pp. 1-33). Stanford, CA: Stanford University Press.

Putnam, R. D. (1993). Making democracy work: Civic traditions in modern Italy. Princeton, NJ: Princeton University Press.

Raz, J. (1979). The authority of law: Essays on law and morality. Oxford, UK: Clarendon Press.

Rheingold, H. (1993). The Virtual community: Homesteading on the electronic frontier. Cambridge, MA: Addison-Wesley.

Roberts, S. T. (2016). Commercial content moderation: Digital laborers' dirty work. In B. M. Tynes \& S. U. Noble (Eds.), The intersectional internet: Race, sex, class, and culture online (pp. 147-160). New York, NY: Peter Lang.

Salmon, C. T., \& Glasser, T. L. (1995). The politics of polling and the limits of consent. In T. L. Glasser \& C. T. Salmon (Eds.), Public opinion and the communication of consent (pp. 437458). New York, NY: Guilford Press.

Schmidt, S. (2018, January 9). Fitness chain bans cable news networks as part of "healthy way of life." Washington Post. Retrieved from https://www.washingtonpost.com/news/morning -mix/wp/2018/01/09/fitness-chain-has-banned-cable-news-networks-as-part-of-healthy -way-of-life/

Schön, D. (1992). Designing as reflective conversation with the materials of a design situation. Knowledge-Based Systems, 5(1), 3-14. Press. 
Scott, M., \& Isaac, M. (2016, September 9). Facebook restores iconic Vietnam War photo it censored for nudity. New York Times. Retrieved from https://www.nytimes.com/2016/09/ 10/technology/facebook-vietnam-war-photo-nudity.html

Sewell, W. (1992). A theory of structure: Duality, agency and transformation. American Journal of Sociology, 98, 1-29. Retrieved from http://en.wikipedia.org/wiki/Structuration_theory

Shapin, S. (1989). The invisible technician. American Scientist, 77(6), 554-563.

Shirky, C. (2008). Here comes everybody: The power of organizing without organizations. New York, NY: Penguin.

Silver, D., \& Massanari, A. (Eds.). (2006). Critical cyberculture studies. New York, NY: NYU Press.

So, J., Kim, S., \& Cohen, H. (2016). Message fatigue: Conceptual definition, operationalization, and correlates. Communication Monographs, 1-25. https://doi.org/10.1080/03637751.2016 .1250429

Soffer, O., \& Gordoni, G. (2017). Opinion expression via user comments on news websites: analysis through the perspective of the spiral of silence. Information, Communication \& Society, 1-16. https://doi.org/10.1080/1369118X.2017.1281991

Squires, C. R. (2002). Rethinking the black public sphere: An alternative vocabulary for multiple public spheres. Communication Theory, 12(4), 446-468. https://doi.org/10.1111/j.1468 -2885.2002 .tboo278.x

Stamos, A. (2018, April 3). Authenticity matters: The IRA has no place on Facebook. Facebook Newsroom. Retrieved from https://newsroom.fb.com/news/2018/04/authenticity-matters/

Star, S. L., \& Ruhleder, K. (1996). Steps toward an ecology of infrastructure: Design and access for large information spaces. Information Systems Research, 7(1), 111-134.

Star, S. L., \& Strauss, A. (1999). Layers of silence, arenas of voice: The ecology of visible and invisible work. Computer Supported Cooperative Work, 8(1-2), 9-30. https://doi.org/10.1023/ a: 1008651105359

Stinson, E. (2017, April 14). The bizarre digital book you must destroy before sharing. Wired. Retrieved from https://www.wired.com/2017/04/bizarre-digital-book-must-destroy-sharing/

Sun, N., Rau, P. P.-L., \& Ma, L. (2014). Understanding lurkers in online communities: A literature review. Computers in Human Behavior, 38, 110-117. https://doi.org/10.1016/j.chb.2014 .05 .022

Sunstein, C. (2001). Republic.com. Princeton, NJ: Princeton University Press.

Thornton, P. (2013, October 8). On letters from climate-change deniers. Los Angeles Times. Retrieved from http://www.latimes.com/opinion/opinion-la/la-ol-climate-change-letters -20131008-story.html

Toff, B., \& Palmer, R. A. (2018). Explaining the gender gap in news avoidance: "News-is-formen" perceptions and the burdens of caretaking. Journalism Studies, 1-17. https://doi.org/ 10.1080/1461670X.2018.1528882

Usher, N., Holcomb, J., \& Littman, J. (2018). Twitter makes it worse: Political journalists, gendered echo chambers, and the amplification of gender bias. International Journal of Press/ Politics. https://doi.org/10.1177/1940161218781254

Verba, S., Schlozman, K. L., \& Brady, H. E. (1995). Voice and equality: Civic voluntarism in American politics. Cambridge, MA: Harvard University Press.

Vranica, S. (2017, June 18). Advertisers try to avoid the web's dark side, from fake news to extremist videos. Wall Street Journal. Retrieved from https://www.wsj.com/articles/advertisers-try -to-avoid-the-webs-dark-side-from-fake-news-to-extremist-videos-1497778201 
Wells, C., Cramer, K. J., Wagner, M. W., Alvarez, G., Friedland, L. A., Shah, D. V., . . Franklin, C. (2017). When we stop talking politics: The maintenance and closing of conversation in contentious times. Journal of Communication, 67(1), 131-157. https://doi.org/10.1111/jcom .12280

Williams, R. (1983). Culture and society: 1780-1950. New York, NY: Columbia University Press. Williams, R. (2006). Culture and materialism. London, UK: Verso.

Wyatt, S., Thomas, G., \& Terranova, T. (2002). They came, they surfed, they went back to the beach: Conceptualising use and non-use of the Internet. In S. Woolgar (Ed.), Virtual society? Technology, cyberbole, reality (pp. 23-40). Oxford, UK: Oxford University Press.

Zhu, Q., Skoric, M., \& Shen, F. (2017). I shield myself from thee: Selective avoidance on social media during political protests. Political Communication, 34(1), 112-131. https://doi.org/10 $.1080 / 10584609.2016 .1222471$

Zweig, D. (2018, February 27). Escaping Twitter's self-consciousness machine. New Yorker. Retrieved from https://www.newyorker.com/tech/elements/escaping-twitters-self -consciousness-machine. 